\title{
Quality of Life in Patients With Cushing's Disease
}

\author{
Alicia Santos ${ }^{1}$, Eugenia Resmini ${ }^{1}, M^{a}$ Antonia Martínez Momblán ${ }^{1,2}$, Elena Valassi ${ }^{1}$, \\ Luciana Martel ${ }^{1}$ and Susan M. Webb ${ }^{1 *}$
}

${ }^{1}$ Endocrinology/Medicine Departments, Hospital Sant Pau, Centro de Investigación Biomédica en Red de Enfermedades Raras (CIBERER, Unidad 747), IIB-Sant Pau, ISCIII and Universitat Autònoma de Barcelona, Barcelona, Spain, ${ }^{2}$ Fundamental and Medico-Surgical Nursing Department, School of Medicine and Health Sciences, University of Barcelona, L'Hospitalet de Llobregat, Spain

Cushing's disease (and by extension, Cushing's syndrome) is a rare disease due to a chronic cortisol excess, which usually has an important impact on quality of life (QoL). It can lead to numerous comorbidities that can interfere with daily life, as fatigability, myopathy, bone loss and fragility, increased cardiovascular risk, depression, and cognitive alterations. Of note, psychological alterations (including depression and anxiety) occur often, and are an important determinant of impaired quality QoL. QoL scores using different questionnaires are poorer in comparison to healthy controls, other pituitary adenomas and some chronic diseases. Even if some improvements can be observed after successful treatment, recovery does not seem to be complete, and comorbidities persist. This persistent QoL impairment has been found using both generic and disease-specific QoL questionnaires, and is also reported by the patients themselves, when asked directly. Multidisciplinary teams are essential to improve patients' well-being. Clinicians should take into account the whole scope of clinical problems and address the different comorbidites associated with the disease. Screening in the psychological sphere, with further intervention if necessary, can be helpful in the management of these patients. Interventions and programs have shown promising results, although there is a need for further development of new strategies for the benefit of these patients.

Keywords: quality of life, health related quality of life, Cushing's syndrome, Cushing's disease, persistent morbidity

\section{INTRODUCTION}

Endogenous Cushing's syndrome (CS) is a rare disease due to a chronic cortisol excess. It affects predominantly women, with a female/male ratio ranges from 3 to 5 (1). Even if the cause of hypercortisolism may vary (being of pituitary, adrenal or ectopic origin), pituitary origin (also called Cushing's disease -CD) is the most common cause of endogenous CS, affecting approximately $70 \%$ of the patients (2). This paper will deal mainly with $\mathrm{CD}$, although some references to relevant studies in CS with a high proportion of patients with CD are also included.

Comorbidities caused by CD can have an important effect on QoL. Some of the symptoms determine physical changes that can easily be perceived by others and may affect patient's social interactions. These include facial plethora, weight gain, central obesity, supraclavicular fat accumulation, hirsutism, acne, purple striae, easy bruising, poor wound healing and ulceration; and also growth retardation in case of children (3). Furthermore, CD can also involve some 
morbidities that may not be easily perceived externally, but greatly affect patients' daily life. These include sleep disturbances, fatigue, myopathy, hypertension, alterations of glucose homeostasis (including diabetes mellitus and insulin resistance), dyslipidemia, prothrombotic state, vascular disease, atherosclerosis, menstrual and libido disturbances, hypogonadism and body composition alterations, including increased fat mass, reduced lean mass, and decreased bone mass leading to osteoporosis (3). Additionally, brain studies have also shown functional and structural alterations in the central nervous system (4). Psychological disturbances may also be present, including depression, anxiety, emotional irritability, apathy and cognitive decline, which may also affect family relationships $(3,5-10)$.

It is important to mention that in clinical practice a wide variety of features are referred by the patients. In the early stages of the disease, they may experience very few symptoms. In other patients it may take years to find the cause of their discomfort (11). In fact, according to data from the European Register on Cushing's syndrome (ERCUSYN), the median delay to diagnosis in patients with CD is 2 years (12). Delay to diagnosis often leads to more pronounced symptoms, which affect daily life, especially when they include psychological disturbances (as anxiety or depression) or troublesome symptoms, as fatigue. This can interfere in social and family relationships, as well as in their professional performance (11). This latter is particularly important, as some patients may be unable to work, with important effects on their income. Data from the ERCUSYN database report that only $47 \%$ of the patients were actively employed, despite a mean age of 44 years (12).

Even if symptoms usually improve after hormonal normalization, some impairment may remain. The recovery is slow and not all symptoms fully reverse. In fact, patients in remission may still have a persistent increased cardiovascular risk, body composition alterations and depression, anxiety or impaired cognition $(6,13-15)$. Furthermore, pituitary deficits requiring hormonal substitution can show up after treatment. Therefore, patients usually complain of incomplete recovery, both physical and psychological, affecting their QoL $(16,17)$.

It is essential to perform periodic, life-long evaluations to properly manage persistent comorbidities in order to improve patient's outcome (17). This also includes QoL and other psychological aspects, which impact on the well-being and even survival of the patients. Of note, depression in patients in remission has been found to increase the hazard of death, and elevate the risk of cardiovascular disease (18). Furthermore, it is also important to consider the perspective of the patient in order to be able to understand and approach all problems globally that $\mathrm{CD}$ may involve. An interesting study reported that $71 \%$ of the patients felt that CS had affected their lives greatly, while $20 \%$ chose "a lot." No patients chose "not at all" or "very little" (8). Therefore, it would be important to consider patient-reported outcomes during follow-up and to provide appropriate multidisciplinary treatment if necessary.

\section{QUALITY OF LIFE AND HEALTH RELATED QUALITY OF LIFE: THE CONCEPTS}

Being a complex concept, different definitions of QoL have been developed. According to the World Health Organization (WHO) QoL can be defined as “an individual's perception of their position in life in the context of the culture and value systems in which they live and in relation to their goals, expectations, standards and concerns" (19). In other words, QoL could be considered a patient-reported measure that reflects their individual definition of well-being (including patients' expectations and physical, emotional and social aspects) (20).

QoL is a widely-used concept that has received growing interest by clinicians and researchers in the last decades. However, when dealing with the effects on QoL that diseases can have, some authors prefer to use a more specific concept: healthrelated QoL. It could be defined as "those aspects of self-perceived well-being that are related to or affected by the presence of disease or treatment" (21).

\section{HOW CAN HEALTH-RELATED QUALITY OF LIFE BE MEASURED?}

Many instruments exist in order to measure health-related QoL. When choosing a tool the essential criterion is to select one that is validated and has good psychometric properties. Questionnaires are the most commonly used tools to measure health-related QoL, as they are easy to use and administer in both clinical practice and research. Many questionnaires exist to measure health-related QoL, and they can be classified as generic and disease-specific.

Generic questionnaires can be used in patients with any disease or even in healthy individuals, which is helpful to make comparisons between different populations. Therefore, it can be interesting to use this kind of questionnaires if we want to compare patients with healthy controls, or if we want to compare patients with different kinds of pituitary adenomas. Some common generic questionnaires are Short-Form 36 (SF36), Short-form 12 (SF-12) or Nottingham Health Profile. However, when dealing with a specific disease, this kind of questionnaires may not approach some particular aspects of the disease (20).

In contrast, disease-specific questionnaires have been developed to evaluate specific QoL aspects of a certain disorder. They are more sensitive to identify specific impairments related to a disease, but as a limitation they can only be used in that specific disease. Therefore, they are more useful for longitudinal analysis in a population with a specific disease (for instance, in the follow-up of a particular patient) or to compare different patients with the same disease $(17,20)$.

In the case of $\mathrm{CD}$, there are two disease-specific questionnaires available: CushingQoL and Tuebingen CD-25. CushingQoL was the first disease-specific questionnaire for CS and is a short questionnaire consisting in 12 questions with a 5-options Likert scale answers, with demonstrated good psychometric properties (22-24). It was initially considered unidimensional, although 
TABLE 1 | Different questionnaires that can be used to assess quality of life in patients with Cushing's disease/syndrome.

\begin{tabular}{|c|c|c|}
\hline & & Questionnaire list \\
\hline \multicolumn{2}{|c|}{$\begin{array}{l}\text { Generic quality of life } \\
\text { questionnaires }\end{array}$} & $\begin{array}{l}\text { Notingham Health Profile (NHP) } \\
\text { Short Form-36 (SF-36) } \\
\text { Short Form-12 (SF-12) (SF-36 in a short } \\
\text { form) } \\
\text { Psychological General Well Being Scale } \\
\text { (PGWBS) } \\
\text { EuroQoL-5D (EQ-5D) } \\
\text { World Health Organization Quality of Life } \\
\text { BREF (WHOQoL-BREF) }\end{array}$ \\
\hline \multicolumn{2}{|c|}{$\begin{array}{l}\text { Disease-specific quality of life } \\
\text { questionnaires }\end{array}$} & $\begin{array}{l}\text { CushingQoL } \\
\text { Tuebingen Cushing's disease quality of life } \\
\text { inventory (Tuebingen CD-25) }\end{array}$ \\
\hline \multirow[t]{8}{*}{ Specific domains: } & Depression & $\begin{array}{l}\text { Hospital Anxiety and Depression Scale } \\
\text { (HADS) } \\
\text { Beck Depression Inventory-II (BDI-II) }\end{array}$ \\
\hline & Anxiety & $\begin{array}{l}\text { Hospital Anxiety and Depression Scale } \\
\text { (HADS) } \\
\text { Beck Anxiety Inventory (BAl) } \\
\text { State Trait Anxiety Inventory (STAl) }\end{array}$ \\
\hline & Fatigue & $\begin{array}{l}\text { Checklist individual strength Questionnaire } \\
\text { (CIS) } \\
\text { Modified Fatigue Impact Scale (MFIS) }\end{array}$ \\
\hline & Self-steem & Rosenberg's questionnaire \\
\hline & Sexual function & $\begin{array}{l}\text { Female Sexual Function Index (FSFI) } \\
\text { International Index of Erectile } \\
\text { Function (IIEF-5) }\end{array}$ \\
\hline & Pain & Mc Gill Pain Questionnaire \\
\hline & Fatigue & Checklist Individual Strength Questionnaire \\
\hline & Sleep & $\begin{array}{l}\text { Pittsburgh Sleep Quality Index (PSQI) } \\
\text { Insomnia Severity Index }\end{array}$ \\
\hline
\end{tabular}

a later analysis has identified two subscales: psychosocial issues and physical problems (25). Of note, a recent study has demonstrated that interpretation of three of the items categorized under psychological issues can vary between different nationalities, making it important to take this into account for interpretation (26). The other questionnaire was developed for patients with CD: the Tuebingen Cushing's disease quality of life inventory (Tuebingen CD-25). This questionnaire consists in 25 questions and includes 6 different domains: Depression, Sexual Activity, Environment, Eating Behavior, Bodily Restrictions and Cognition $(27,28)$. In this questionnaire lower scores indicate a better QoL (in contrast with CushingQoL). Less studies are available with this questionnaire, although some psychometric properties had been demonstrated, as high reliability and validity, sensitivity to change and construct and criterion validity $(27,29$, $30)$. A strong correlation has been found when comparing scores of both CushingQoL and Tuebingen CD-25 ( $\mathrm{R}=-0.733)(30)$.

There are also other types of questionnaires that may not be directly considered QoL questionnaires, although they are able to measure a specific domain which considerably impacts on QoL. These include comorbidities as depression, anxiety, fatigue, sexual function, sleep, pain, or self-steem (20). Table 1 summarizes different questionnaires that can be used to assess health-related QoL in patients with CD.

\section{WHAT ARE THE EFFECTS OF CUSHING'S SYNDROME ON HEALTH-RELATED QUALITY OF LIFE?}

It is now clear that CS and CD have a deleterious effect on the QoL of the affected patients, although the extent may vary from one patient to another. Different determinants have been described that impact on quality of life (12, 22, 29, 31-42). A summary can be found in Figure 1 .

There are important differences in QoL between patients with active disease and patients in remission of CD. Therefore, two separate sections to analyzing QoL during the different phases of the disease are presented.

\section{EFFECTS OF ACTIVE DISEASE ON QUALITY OF LIFE}

Quality of life is clearly impaired in patients with active disease. In CD QoL is worse than in controls and patients with any other kind of pituitary adenomas $(35,43)$. QoL is similarly impaired in pituitary-dependent CD and other causes of CS, as shown in a cohort of patients from different European countries included in the ERCUSYN database using CushingQoL and EuroQoL $(12,34)$.

SF-36 results are low in physical and mental summary scores compared to healthy controls matched for age and sex $(35,44)$. When compared to other untreated pituitary tumors (which not have been treated) $\mathrm{CD}$ were the patients with most impairment in all SF-36 measures (43). This impairment is especially relevant if patients do not achieve remission after treatment (specifically, scores $<25$ th percentile for age and sex in most of the SF-36 domains) (45). Negative correlations have been found between $24 \mathrm{~h}$ urinary free cortisol and the mental component score of SF36 (but not with the physical component score) in patients with $\mathrm{CD}(32)$.

Medical treatment can be helpful to improve QoL in active disease. In a sample of 162 patients treated with pasireotide, a mean improvement in CushingQoL of 11.1 points was found after 12 months (46). Further analysis of the sample revealed that QoL improvements were associated to lowering of urinary free cortisol levels, reduction of both BMI and weight, and improvement in depression (47). Twenty-four-week treatment with mifepristone in CS has also been shown to improve the mental and physical scores of SF-36 and depression, measured by BDI-II (48). In a small sample of 17 patients using different drugs sequentially (pasireotide, ketoconazole or cabergoline) during 80 days, no statistical changes in QoL were found when compared to basal values (no improvement or worsening). However, improvement was found after 1 year in 3 patients that continued medical treatment, suggesting that QoL improvements after medical therapy may be found in the long run, but not so much short-term (49).

Depression is typically found in patients with $\mathrm{CD}$ and is suggested to be an early manifestation of CS $(3,50)$. At the disease onset (or even before diagnosis) it is present in up to $25 \%$ of the patients, and the percentage may increase over time if the disease 


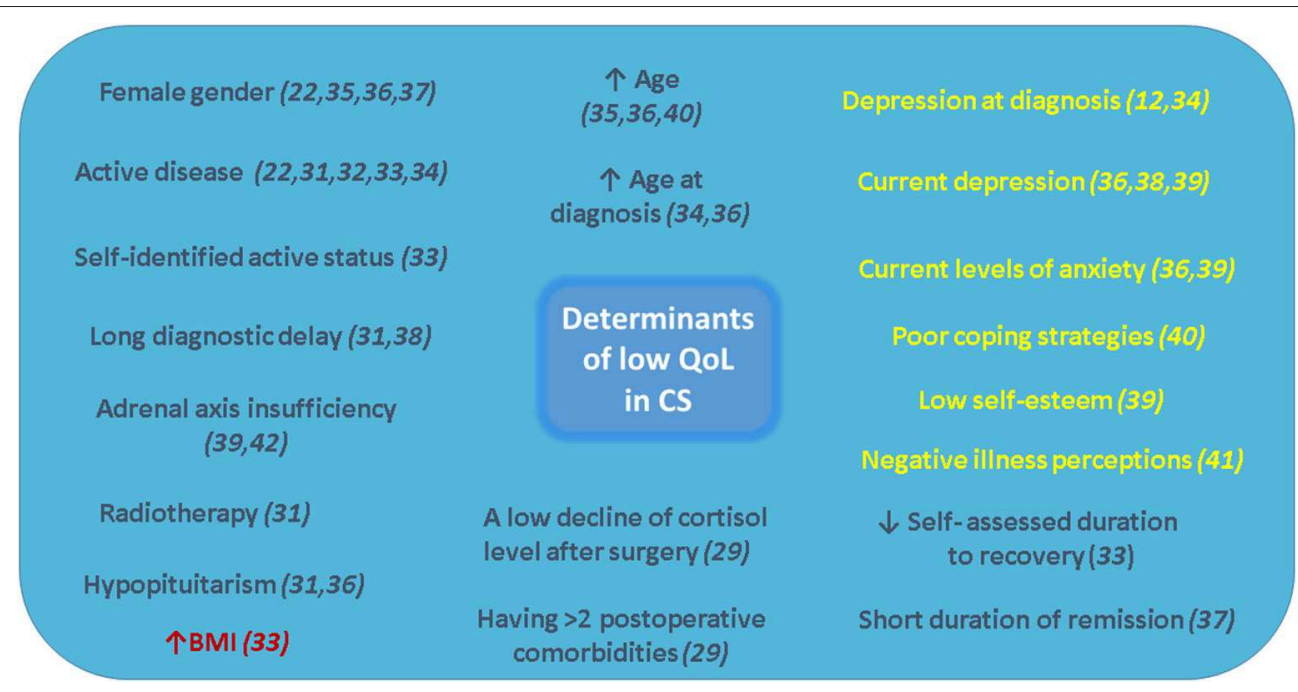

FIGURE 1 | Determinants of low quality of life in Cushing's syndrome. Modifiable factors using specific interventions have been highlighted (yellow for psychological determinants and red for BMI).

is not treated (10). Data from the ERCUSYN have reported it in $38 \%$ of the patients at diagnosis (12). When using specific diagnostic criteria, major depressive disorder has been reported in $50-80 \%$ of the active patients according to different studies, with higher presence in the older studies (10). Furthermore, the level of depression correlates with QoL scores measured with SF-36 in female patients with CS, who are clearly worse than controls (44).

Anxiety is also more prevalent in CS than in healthy population, as evidenced with questionnaires like STAI (51). It seems to be more prevalent in pituitary-dependent CD that in other causes of CS (52). One study using specific diagnostic criteria found that generalized anxiety disorder was present in $79 \%$ of the patients, while panic disorder was found in a variable range from 3 to $37 \%$ of the patients, possibly associated with a more chronic stage of the disease $(10,53,54)$. Other psychiatric disorders reported include mania or hypomania (3-30\% of the patients) and psychotic disorders (8\% of the patients, but more common in adrenal carcinomas, where it was found in up to $40 \%$ of the patients) $(10,55-57)$. Obsessive-compulsive disorder has also been observed in children (3).

Cognitive alterations are also commonly found in patients suffering from CD. Memory is the cognitive function most frequently studied, with impairment in both verbal and visual memory (51, 58-62). Although less consistently, impairment has also been found in other cognitive functions like executive functions, visoconstructive skills, language, motor functions and information processing speed (63).

This poor cognitive performance appears to be related to specific brain specific alterations. For instance, smaller hippocampal volumes have been found in active patients than in controls, which have been related to learning and memory dysfunction, and also to cortisol blood levels (64). Adult patients with active disease also have smaller cerebellar cortex and right amygdala volumes than healthy controls $(51,65)$. Reduced amygdala volumes in comparison to controls have also been found in children with CS (66). Left amygdala volumes are negatively correlated with depression and anxiety scores in active CS (but not in patients in remission) (65). Interestingly, right cerebellar cortex volumes correlated with QoL scores, while left cerebellar cortex volumes correlated with visual memory (51). Other brain dysfunctions present in active CS include changes in the concentration of different brain metabolites like the choline/creatine ratio on the frontal and thalamic areas (67), diffuse alterations in white matter integrity suggesting demyelization (68) and altered activation in different brain structures important for emotion perception (69).

Finally, other specific symptoms may have an important impact in patient's lives. Many suffer from insomnia, specifically middle insomnia (59\%), late insomnia (57\%), or early insomnia (29\%) (70). Furthermore, although sexual function has not often been investigated in $\mathrm{CD}$, it is frequently impaired. Reduced libido is reported in $50-69 \%$ of patients with active CS $(10,12,55,70)$. A study in a sample of 29 sexually-active women with active CS (89.7\% with CD) showed that female sexual dysfunction was present in $88.9 \%$ of the patients. Scores of the Female Sexual Function Index (FSFI) were lower than in healthy controls. More specifically, lower scores for arousal, lubrication, orgasm, satisfaction and higher levels and frequency of pain during intercourse were found, while no differences were found for sexual desire. FSFI scores were positively correlated with $\mathrm{LH}$ levels (which were lower in the patient sample compared with controls) (44).

QoL is also impaired in children and adolescents. Female to male prevalence decreases with younger age, and in fact in prepuberal children the disease seems to be more prevalent in males (71). Children with $\mathrm{CD}$ can experiment personality changes, which typically include compulsive behavior, moodiness, irritability and overachievement in school (72). Some authors have reported altered amygdala and hypocampal 
function during a faces encoding task (which assesses emotional encoding and memory), in adolescents with CS, which is not related to memory and affective systems, in contrast with findings in adult patients (73).

\section{EFFECTS OF REMISSION IN QUALITY OF LIFE}

Patients in remission of CS have better QoL than active patients measured with both disease-specific and generic questionnaires $(23,35)$. The origin of the disease does not seem influence QoL, which was similarly impaired in patients with CS, irrespective of the cause (37). After successful treatment, improvement often takes months or over a year, while the immediate postoperative phase can be troublesome, including more pain, fatigability and a poor perception of QoL (22). This in part may be due to the glucocorticoid withdrawal syndrome, which occurs after successful surgery. If the patient is not aware of this, the first weeks after surgery can prove very cumbersome and worrying. A study on patients after adrenalectomy (including $28 \%$ of patients with $\mathrm{CD}$ ) found that mean time for symptom resolution was at least 7 months, and some symptoms as acne took up to a mean of 17 months to resolve (74). In fact, not all patients perceived themselves as fully recovered. For instance, in a cohort of 102 patients treated for CD $92 \%$ of the patients reached criteria for biochemical cure, while only $80.4 \%$ perceived themselves as in remission (33).

Significant improvement from baseline values can be detected with CushingQoL 4 months after successful transsphenoidal surgery (23). Using Tubingem 25-CD in a sample of 17 patients with $\mathrm{CD}$, improvement was found after surgery in most of the domains, including sexual activity, environment, eating behavior, bodily restrictions and cognition. However, no improvement was found for depression. Predictors for improvement in QoL after surgery were preoperative QoL impairment (meaning that patients with poorer QoL preoperatively were more likely to improve post surgery) and age (meaning that younger patients were more likely to improve post surgery) (29). Another study reported impairment in the 6 dimensions of Tuebingem 25$\mathrm{CD}$ questionnaire in patients treated for CD $(85 \%$ in remission after surgery) (75). In addition, women were more affected than men for the dimensions of eating behavior and cognition of the Tuebingem 25-CD questionnaire (40).

Improvements in QoL have also been reported using generic questionnaires in patients with $\mathrm{CD}$ after transsphenoidal surgery. More specifically, using SF-36, improvements were found for bodily pain, vitality, social functioning, role limitations due to emotional health, general health, mental health and mental summary scores; while no improvement was found for physical functioning, role limitations for physical health and physical summary (35). SF-36 scores in patients surgically treated for $\mathrm{CD}$ have showed more impairment in women, specifically for physical functioning, physical role functioning and emotional role functioning (40).

Negative illness perceptions in patients in remission of CS are another feature which negatively affect QoL. Correlations between the Illness Perception Questionnaire Revised (IPQ-R), and QoL questionnaires (CushingQoL and the visual analog scale of EuroQoL) have reflected that a worse QoL is related to affected illness perceptions (41).

However, improvement in QoL after remission is not complete in most of the cases, and some degree of impairment tends to persist after cure $(35,36,76)$. Table 2 reflects a list of the most common symptoms still present after surgical remission in patients with CS. Patients in remission still have poorer QoL scores than healthy controls. Generic questionnaires have shown impairment in comparison to healthy population and normative values using different questionnaires, like the Nottingham Health Profile (36), WHOQoL-BREF (39) or both mental and physical summary scores of SF-36 $(35,36,75)$. In addition, patients in long-term follow-up of CD show impaired physical functioning, measured with SF-36, when compared to patients with non-functioning adenomas (77). CushingQoL scores are associated with depression, anxiety, cortisol insufficiency and self-steem (39). In a big cohort of patients included in the ERCUSYN database, 1 year after treatment patients with CD pituitary origin had worse QoL than those of adrenal origin. However, in a regression analysis etiology was not related to QoL after adjustment for baseline age, gender, remission status, duration of active CS, glucocorticoid dependency and follow-up time. Furthermore, when different symptoms at diagnosis were included in a regression analysis (hypertension, diabetes mellitus, muscle weakness, and depression) only depression was associated with a worse CushingQoL score at last follow-up visit (34).

The presence of persistent comorbidities can also have an important role on patient's quality of life. In fact, having more than two postoperative comorbidities has been reported as a predictor of low quality of life (29). These may include hypertension, dyslipidemia, central obesity or persistent diabetes mellitus, among others, leading to an increased cardiovascular risk (13). In patients treated for Cushing's syndrome, increased BMI has been reported as predictor of poorer quality of life (measured with CushingQoL) (33). Control of certain comorbidities like diabetes may require specific additional

TABLE 2 | Most common symptoms still present in patients in remission of CS after surgical remission [adapted from Lindsay et al. (35); sample of 343 patients with a mean time since treatment of 11.8 years].

\begin{tabular}{lclc}
\hline Symptom & $\begin{array}{c}\text { Percentage of } \\
\text { patients reporting } \\
\text { the symptoms (\%) }\end{array}$ & Symptom & $\begin{array}{c}\text { Percentage of } \\
\text { patients reporting } \\
\text { the symptoms (\%) }\end{array}$ \\
\hline Fatigue & 41.3 & $\begin{array}{l}\text { Bulging } \\
\text { abdomen }\end{array}$ & 29.3 \\
Forgetfulness & 35.7 & Anxiety & 28.4 \\
Trouble sleeping & 33.3 & Facial hair & 27.6 \\
Depression & 31.2 & Feelings of & 27.6 \\
Weight gain & 30.4 & $\begin{array}{l}\text { Sadness } \\
\text { Mood swings }\end{array}$ & 27.4 \\
$\begin{array}{l}\text { Decreased muscle } \\
\text { strength or }\end{array}$ & 30.4 & $\begin{array}{l}\text { Decreased ability } \\
\text { to exercise }\end{array}$ & 27.0 \\
Weakn & & &
\end{tabular}

weakness 
chronic medication and lifestyle changes, which may influence patient's perception of well-being.

Self-assessment of the remission status provides some interesting information, and may be discordant with the biochemical status. In a cohort of 102 patients treated for $\mathrm{CD}$, CushingQoL scores were higher in patients that perceived themselves as in remission when compared to patients that perceived themselves as having persistent disease. This group that perceived themselves as biochemically cured also had lower scores in anxiety and depression, measured with HADS. When patients with real biochemical remission were analyzed, those who perceived themselves as cured had better QoL than patients who did not feel "cured," although they also had a longer duration of follow-up. The authors suggested that this may reflect a discordance between biochemical and psychological recovery times, psychological recovery being slower. On the other hand, patients who were hypercortisolemic had poorer QoL scores and higher depression scores compared to patients who were biochemically cured (33).

Patients perceive that their body changes dramatically after onset of the disease, and that it never returns to its original size. However, no clear relationship was found between QoL and characteristics of a drawing test, were patients drew themselves before, during and after CS treatment (78). Patients in remission of CS also showed a lower body satisfaction in comparison with normative values measured with the Body Satisfaction Score. Body satisfaction is also associated with the social relations domain of the WhoQoL questionnaire. In the same study, $61.9 \%$ of the patients had a low or very low self-steem (39).

Hypopituitarism contributes to worse QoL in patients treated for CD. In a longitudinal study of 58 patients who had undergone transsphenoidal surgery (and radiotherapy in 19\% of the patients), hypopituitarism was present in $52 \%$ of the patients, and was an independent predictor of worse QoL (36). In line with these findings, a study of 99 patients with $\mathrm{CD}$ and 24 patients with CS of adrenal origin found that both groups had impairment in most of the QoL dimensions compared to controls (with no differences between both patient groups). However, when pituitary patients were analyzed, patients without any pituitary deficiencies had better QoL scores (specifically in CushingQoL and the energy item of the NHP questionnaire) and also in the items of fatigue and motivation form the Checklist Individual Strength Questionnaire (a questionnaire designed to measure fatigue) when compared to patients with deficiencies. Even if impairment was still present in comparison to controls, in the group without pituitary deficiencies it was only found in half of the dimensions evaluated (37). Other studies have also found higher fatigue in CS patients in remission than in healthy controls, measured with MFI-20 and MFS $(36,79)$.

Patients with $\mathrm{CD}$ that underwent bilateral adrenalectomy, compared to patients who underwent other treatments, had poorer QoL, measured with SF-36 (mainly in bodily pain, general health, vitality and social functioning) and CushingQoL. They also presented worse depressive scores measured with the BDI. The major predictor of poor QoL was adrenal insufficiency (42). This is in line with a prior study, where even if patients reported improvement in their QoL after bilateral adrenalectomy, scores from SF-36 were all lower that the general population (80).
Different studies have described higher depression and anxiety levels in comparison with literature values, healthy controls and non-functioning adenomas, measured with different questionnaires, including HADS, BDI, BDI-II and or STAI $(36,37,51,75,81,82)$. Increased age and male gender have been related to less anxiety levels in a cohort of patients treated by transsphenoidal surgery for CD (33). Current depression scores, measured with BDI-II and CES-D, have been associated to delay to diagnosis in patients in remission of CS (38). Patients had higher scores than controls for depression, anxiety, stress perception and QoL. Interestingly, levels of blood brain-derived neurotrophic factor (usually expressed in brain areas that control mood and stress response), were related to higher depression, anxiety and stress, and to decreased affective balance (38).

Another study found that patients in remission of CD presented higher depression, anxiety, apathy and irritability than healthy controls. Depression (measured with HADS) was positively influenced by remission duration; while irritability (measured with the Irritability Scale) was related to radiotherapy, and on the other hand apathy (measured with the Apathy Scale) was associated by level of education. Those patients also presented maladaptative personality traits, with poorer performance in several scales of the Dimensional Assessment of Personality Pathology short-form in comparison with controls. Of note, when anxiety and depression were controlled as covariates only differences in affective liability and anxiousness remained statistically significant (81). In another study from the same group it was demonstrated that patients with pituitary adenomas had less effective coping strategies than healthy controls, although patients with CD sought more social support than patients with non-functioning adenomas (83). In a focus group study including 6 patients with $\mathrm{CD}$ some maladaptive coping strategies (as overdoing or problems with acceptance) were identified as possible contributors of low QoL (84). In fact, a further study found that maladaptative coping strategies (mainly depressive coping, trivialization, and wishful thinking) were correlated to different measures, indicating a relationship with poorer QoL (measures with both Tuebingem CD-25 and SF-36) and higher depression, anxiety and embitterment (40). Furthermore, QoL scores were also related to embitterment (measured with the Bern embitterment questionnaire-BEI). Some degree of embitterment was found in more than a half of the patients compared to reference values. Specifically $36.8 \%$ of the patients had a medium degree of embitterment, $18.7 \%$ had an above-average degree of embitterment and 3.5\% had an extreme degree of embitterment (40)

Cognitive function, including memory and executive functions, remains impaired after cure of $\mathrm{CD}$. This has been found 1 year after biochemical cure $(85,86), 3$ years after surgery for CS (9) and also in patients with long-term remission, with lower scores when compared to healthy controls and non-functioning adenomas $(6,82,87,88)$. One study in CS in long-term remission reported that cognitive alterations were independent of concomitant fatigue and affective disorders, while etiology was not related to cognitive symptoms (82).

In line with findings for cognitive function, brain alterations may also persist in patients in remission. They include altered functionality (as changes in the concentrations of different brain 
metabolites or loss of white matter integrity due to decreases of axial diffusivity) (89-93) and structure $(4,7,88)$, with lower brain volumes than controls in adults (affecting total volumes and gray matter) (51). Subjective loss of brain volume can also be found in $86 \%$ of the patients with CD after cure (94). In contrast, in children reduced brain volumes seem to reverse after cure (66). Some authors report a slight increase of the hippocampus and right caudate volume after cure of CD (95, 96). Hippocampal volume increase was also related to word learning improvement (95). Other studies in patients in remission of CS have found no differences in hippocampal volumes, when compared to healthy controls $(7,97)$, although smaller hippocampal volumes were found in patients with severe memory impairments (97). Of note, brains of patients in remission show a higher degree of white matter lesions (visible in the MRI) when compared to controls and patients with active disease. The severity of white matter lesions has been correlated to duration and degree of hypertension, reflecting the increased prevalence of cardiovascular risk factors in CS. Furthermore, lower gray and total brain matter volumes have been found when compared to normal controls, and brain volume was correlated to 10 -year cardiovascular risk (6).

Even after surgery children may also still experience low QoL, although improvements may be found in comparison to levels during active disease (98). In a sample of children and adolescents, incomplete recovery of the hypothalamicpituitary-adrenal axis 1 year post-treatment was related to poorer QoL in physical and psychosocial domains, measured with a generic health-related QoL questionnaire (the child health questionnaire-parent report). Furthermore, changes in physical function scores were inversely associated with BMI (98). Most of the persistent comorbidities found in adults, as altered body composition, can also be found in children (99). However, brain function and volume seems to be affected by cortisol excess in a different way when compared to adults. In fact, a recovery of brain volume has been described 1 year after cure, with a decrease in cognitive function and a decline in school performance, with no associated psychopathology (66). Brain plasticity in these younger patients may contribute to these findings which differ from the experience in adults. Furthermore, in children with CS, final height is very often compromised, lower than midparent height (100).

\section{HINTS TO IMPROVE PATIENT'S QUALITY OF LIFE}

Clinicians play an important role in helping patients to improve their QoL. First of all, it is important to treat all comorbidities. As reported before, some modifiable factors can have a great impact in QoL (as depression, anxiety, poor coping strategies, low selfsteem, negative illness perceptions or high BMI). Patients should be asked for their symptoms and needs and referred to specialists if necessary, including psychologists and/or psychiatrists. It would also be important to inform the patients on the persistent adverse events that CS may have on their QoL, so inappropriate expectations can be avoided (77). Giving printed information may be helpful, so the patients can have time to analyze and review it if necessary. Additionally, an empathic relationship is essential, as in fact the doctor-patient relationship can have an important impact on patient outcome, and even survival (101).

Patients with CS of any cause may benefit from educational interventions. A 9-month educational nursing program in patient groups with CS (most of them in remission) demonstrated improvements in sleep patterns, pain, healthy lifestyle and physical activity, which positively influenced QoL. This program consisted on 4 educational sessions (2 of them including also family members) and one follow-up visit. The topics included basic information of CS, management of comorbidities, self-care, practice of balanced diets and recommendations for healthy lifestyle (102). In this line, the Endocrine Society Guidelines recommend educating patients with CS on the clinical features of remission of CS, but also their families (103). Given the low prevalence of the disease (approximately 39.1 patients per million inhabitants) patients may feel very lonely and not understood (104). Therefore, support groups can also be helpful to help patients deal with CS and its consequences. Many options exist, which do not need to be face-to-face (facebook, whatsapp or websites can be used). Clinicians can facilititate contacts to the patients if local groups are available. Finally, maintaining healthy habits and lifestile is also important, positively influencing patient outcome and well-being (10).

A study on German and US patients with CS in remission (only CD for Germany) explored patient's needs through a questionnaire. Patients reported that good medical care and skilled doctors where what helped them most to cope with the disease ( $48.8 \%$ US, $44.4 \%$ Germany), followed by support from family, friends and religion (36.9\% US, 31.7\% Germany). Regarding educational and support programs, most of the patients preferred internet-based programs (89.3\% US, 75.4\% Germany). However, cultural differences and specific needs may differ in different populations of patients with CS (105). In other chronic diseases programs that improve self-manegement (where the patient has a more active role) have lead to better health status and increased QoL (105). Consequently, it would be helpful to develop specific programs for patients with CD too.

In conclusion, health-care providers can use different strategies to improve patient's well-being. Screening and management of persistent comorbidities, including psychological aspects, is essential. Education on the disease and what to expect can be very helpful, as well as an empathic attitude, to make the patient aware that the symptoms, signs and limitations he or she is experiencing may be related to the prior diagnosis of $\mathrm{CS}$, and can be approached to improve their day-to-day outcome. Group programs have shown promising results, but still few are available, so this is a pending issue for the future.

\section{AUTHOR CONTRIBUTIONS}

AS wrote the manuscript. ER and MM helped with the literature review and editing. All authors revised the manuscript. 


\section{REFERENCES}

1. Newell-Price J, Bertagna X, Grossman AB, Nieman LK. Cushing's syndrome. Lancet. (2006) 367:1605-17. doi: 10.1016/S0140-6736(06)68699-6

2. Boscaro M, Barzon L, Fallo F, Sonino N. Cushing's syndrome. Lancet. (2001) 357:783-91. doi: 10.1016/S0140-6736(00)04172-6

3. Arnaldi G, Angeli A, Atkinson AB, Bertagna X, Cavagnini F, Chrousos GP, et al. Diagnosis and complications of Cushing's syndrome: a Consensus Statement. J Clin Endocrinol Metab. (2003) 88: 5593-602. doi: 10.1210/jc.2003-030871

4. Andela CD, van Haalen FM, Ragnarsson O, Papakokkinou E, Johannsson G, Santos A, et al. MECHANISMS IN ENDOCRINOLOGY: Cushing's syndrome causes irreversible effects on the human brain: a systematic review of structural and functional magnetic resonance imaging studies. Eur J Endocrinol. (2015) 173:R1-14. doi: 10.1530/EJE-14-1101

5. Dimopoulou C, Ising M, Pfister H, Schopohl J, Stalla GK, Sievers C. Increased prevalence of anxiety-associated personality traits in patients with Cushing's disease: a cross-sectional study. Neuroendocrinology. (2013) 97:139-45. doi: 10.1159/000338408

6. Santos A, Resmini E, Gómez-Ansón B, Crespo I, Granell E, Valassi $\mathrm{E}$, et al. Cardiovascular risk and white matter lesions after endocrine control of Cushing's syndrome. Eur J Endocrinol. (2015) 173:765-75. doi: 10.1530/EJE-15-0600

7. Andela CD, van der Werff SJ, Pannekoek JN, van den Berg SM, Meijer OC, van Buchem MA, et al. Smaller grey matter volumes in the anterior cingulate cortex and greater cerebellar volumes in patients with long-term remission of Cushing's disease: a case-control study. Eur J Endocrinol. (2013) 169:811-9. doi: 10.1530/EJE-13-0471

8. Gotch PM. Cushing's syndrome from the patient perspective. Endocrinol Metab Clin North Am. (1994) 23:607-17. doi: 10.1016/S0889-8529(18)30087-2

9. Forget H, Lacroix A, Bourdeau I, Cohen H. Long-term cognitive effects of glucocorticoid excess in Cushing's syndrome. Psychoneuroendocrinology. (2016) 65:26-33. doi: 10.1016/j.psyneuen.2015.11.020

10. Santos A, Resmini E, Pascual JC, Crespo I, Webb SM. Psychiatric symptoms in patients with Cushing's syndrome: prevalence, diagnosis and management. Drugs. (2017) 77:829-42. doi: 10.1007/s40265-017-0735-z

11. Santos A, Webb SM. Coping with Cushing's syndrome. The patients' perspectives. In: Laws ER Jr., editor. Cushing's Disease an Often Misdiagnosedand Not so Rare Disorder. Amsterdam: Elsevier Academic Press. (2017). p. 170-85. doi: 10.1016/B978-0-12-804340-0.00010-3

12. Valassi E, Santos A, Yaneva M, Tóth M, Strasburger CJ, Chanson P, et al. ERCUSYN Study Group. The European Registry on Cushing's syndrome: 2-year experience. Baseline demographic and clinical characteristics. Eur J Endocrinol. (2011) 165:383-92. doi: 10.1530/EJE-11-0272

13. Colao A, Pivonello R, Spiezia S, Faggiano A, Ferone D, Filippella M, et al. Persistence of increased cardiovascular risk in patients with Cushing's disease after five years of successful cure. J Clin Endocrinol Metabol. (1999) 84:266472. doi: $10.1210 /$ jcem. 84.8 .5896

14. Barahona MJ, Sucunza N, Resmini E, Fernández-Real JM, Ricart W, MorenoNavarrete JM, et al. Persistent body fat mass and inflammatory marker increases after long-term cure of Cushing's syndrome. J Clin Endocrinol Metab. (2009) 94:3365-71. doi: 10.1210/jc.2009-0766

15. Dichtel LE, Schorr M, Gill CM, Economopoulos KP, Gerweck AV, Swearingen B, et al. Body composition in pituitary, adrenal and iatrogenic Cushing's syndrome and effects of DHEAS levels. Clin Endocrinol. (2017) 86:160-2 doi: 10.1111/cen.13251

16. Pikkarainen L, Sane T, Reunanen A. The survival and well-being of patients treated for Cushing's syndrome. J Intern Med. (1999) 245:463-8. doi: 10.1046/j.1365-2796.1999.00483.x

17. Webb SM, Santos A, Resmini E, Martínez-Momblán MA, Martel L, Valassi E. Quality of Life in Cushing's disease: a long term issue? Ann Endocrinol. (2018) 79:132-7. doi: 10.1016/j.ando.2018.03.007

18. Lambert JK, Goldberg L, Fayngold S, Kostadinov J, Post KD, Geer EB. Predictors of mortality and long-term outcomes in treated Cushing's disease: a study of 346 patients. J Clin Endocrinol Metab. (2013) 98:1022-30. doi: $10.1210 /$ jc.2012-2893
19. Study protocol for the World Health Organization project to develop a Quality of Life assessment instrument (WHOQOL). Qual Life Res. (1993) 2:153-9. doi: 10.1007/BF00435734

20. Webb SM, Crespo I, Santos A, Resmini E, Aulinas A, Valassi E. MANAGEMENT OF ENDOCRINE DISEASE: quality of life tools for the management of pituitary disease. Eur J Endocrinol. (2017) 177:R13-26. doi: 10.1530/EJE-17-0041

21. Ebrahim S. Clinical and public health perspectives and applications of health-related quality of life measurement. Soc Sci Med. (1995) 41:1383-94. doi: 10.1016/0277-9536(95)00116-O

22. Webb SM, Badia X, Barahona MJ, Colao A, Strasburger CJ, Tabarin A, et al. Evaluation of health-related quality of life in patients with Cushing's syndrome with a new questionnaire. Eur J Endocrinol. (2008) 158:623-30. doi: 10.1530/EJE-07-0762

23. Santos A, Resmini E, Martínez-Momblán MA, Crespo I, Valassi E, Roset $\mathrm{M}$, et al. Psychometric performance of the CushingQoL questionnaire in conditions of real clinical practice. Eur J Endocrinol. (2012) 167:337-42. doi: 10.1530/EJE-12-0325

24. Nelson LM, Forsythe A, McLeod L, Pulgar S, Maldonado M, Coles T et al. Psychometric evaluation of the Cushing's Quality-of-Life questionnaire. Patient. (2013) 6:113-24. doi: 10.1007/s40271-013-0012-5

25. Tiemensma J, Depaoli S, Felt JM. Using subscales when scoring the Cushing's quality of life questionnaire. Eur J Endocrinol. (2016) 174:33-40. doi: 10.1530/EJE-15-0640

26. Winter SD, Depaoli S, Tiemensma J. Assessing differences in how the CushingQoL is interpreted across countries: comparing patients from the U.S. and the Netherlands. Front Endocrinol. (2018) 9:368. doi: $10.3389 /$ fendo. 2018.00368

27. Milian M, Teufel P, Honegger J, Gallwitz B, Schnauder G, Psaras T. The development of the Tuebingen Cushing's disease quality of life inventory (Tuebingen CD-25). Part I: construction and psychometric properties. Clin Endocrinol. (2012) 76:851-60. doi: 10.1111/j.1365-2265.2011.04191.x

28. Milian M, Teufel P, Honegger J, Gallwitz B, Schnauder G, Psaras T. The development of the Tuebingen Cushing's disease quality of life inventory (Tuebingen CD-25). Part II: normative data from 1,784 healthy people. Clin Endocrinol. (2012) 76:861-7. doi: 10.1111/j.1365-2265.2011.04280.x

29. Milian M, Honegger J, Teufel P, Wolf A, Psaras T. Tuebingen CD-25 is a sensitive tool to investigate health-related quality of life in Cushing's disease patients in the course of the disease. Neuroendocrinology. (2013) 98:188-99. doi: $10.1159 / 000355622$

30. Milian M, Kreitschmann-Andermahr I, Siegel S, Kleist B, Führer-Sakel D, Honegger J, et al. Validation of the tuebingen CD-25 inventory as a measure of postoperative health-related quality of life in patients treated for Cushing's disease. Neuroendocrinology. (2015) 102:60-7. doi: 10.1159/000431022

31. Papoian V, Biller BM, Webb SM, Campbell KK, Hodin RA, Phitayakorn R. Patients' perception on clinical outcome and quality of life after a diagnosis of Cushing syndrome. Endocr Pract. (2016) 22:51-67. doi: 10.4158/EP15855.OR

32. Vega-Beyhart A, Enriquez-Estrada VM, Bello-Chavolla OY, Torres-Victoria TR, Martínez-Sánchez FD, López-Navarro JM, et al. Quality of life is significantly impaired in both secretory and non-functioning pituitary adenomas. Clin Endocrinol. (2019) 90:457-67. doi: 10.1111/cen.13915

33. Carluccio A, Sundaram NK, Chablani S, Amrock LG, Lambert JK, Post KD et al. Predictors of quality of life in 102 patients with treated Cushing's disease. Clin. Endocrinol. (2015) 82, 404-11. doi: 10.1111/cen.12521

34. Valassi E, Feelders R, Maiter D, Chanson P, Yaneva M, Reincke M, et al. Worse Health-Related Quality of Life at long-term follow-up in patients with Cushing's disease than patients with cortisol producing adenoma. Data from the ERCUSYN. Clin Endocrinol. (2018) 88:787-98. doi: 10.1111/cen.13600

35. Lindsay JR, Nansel T, Baid S, Gumowski J, Nieman LK. Long-term impaired quality of life in Cushing's syndrome despite inicial improvement after surgical remission. J Clin Endocrinol Metab. (2006) 91:447-53. doi: 10.1210/jc.2005-1058

36. van Aken MO, Pereira AM, Biermasz NR, van Thiel SW, Hoftijzer HC, Smit JW, et al. Quality of life in patients after long-term biochemical cure of Cushing's disease. J Clin Endocrinol Metab. (2005) 90:3279-86. doi: 10.1210/jc.2004-1375 
37. Wagenmakers MAEM, Netea-Maier RT, Prins JB, Dekkers T, Den Heijer M, Hermus ARMM. Impaired quality of life in patients in long-term remission of Cushing's syndrome of both adrenal and pituitary origin: a remaining effect of long-standing hypercortisolism? Eur J Endocrinol. (2012) 167:68795 doi: 10.1530/EJE-12-0308

38. Valassi E, Crespo I, Keevil BG, Aulinas A, Urgell E, Santos A, et al. Affective alterations in patients with Cushing's syndrome in remission are associated with decreased BDNF and cortisone levels. Eur J Endocrinol. (2017) 176:22131. doi: 10.1530/EJE-16-0779

39. Vermalle M, Alessandrini M, Graillon T, Paladino NC, Baumstarck K, Sebag F, et al. Lack of functional remission in Cushing's syndrome. Endocrine. (2018) 61:518-25. doi: 10.1007/s12020-018-1664-7

40. Siegel S, Milian M, Kleist B, Psaras T, Tsiogka M, Führer D, et al. Coping strategies have a strong impact on quality of life, depression, and embitterment in patients with Cushing's disease. Pituitary. (2016) 19:590600. doi: 10.1007/s11102-016-0750-1

41. Tiemensma J, Kaptein AA, Pereira AM, Smit JW, Romijn JA, Biermasz NR. Negative illness perceptions are associated with impaired quality of life in patients after long-term remission of Cushing's syndrome. Eur J Endocrinol. (2011) 165:527-35. doi: 10.1530/EJE-11-0307

42. Sarkis P, Rabilloud M, Lifante JC, Siamand A, Jouanneau E, Gay E, et al. Bilateral adrenalectomy in Cushing's disease: Altered long-term quality of life compared to other treatment options. Ann Endocrinol. (2019) 80:32-7. doi: 10.1016/j.ando.2018.01.002

43. Johnson MD, Woodburn CJ, Vance ML. Quality of life in patients with a pituitary adenoma. Pituitary. (2003) 6:81-7. doi: 10.1023/B:PITU.0000004798.27230.ed

44. Keskin FE, Özkaya HM, Ortaç M, Salabaş E, Kadioglu A, Kadioglu P. Sexual function in women with Cushing's Syndrome: a controlled study. Turk J Urol. (2018) 44:287-93. doi: 10.5152/tud.2018.74240

45. Lindholm J, Juul S, Jorgensen JO, Astrup J, Bjerre P, Feldt-Rasmussen $\mathrm{U}$, et al. Incidence and late prognosis of Cushing's syndrome: a population-based study. J Clin Endocrinol Metab. (2001) 86:117-23. doi: $10.1210 /$ jcem.86.1.7093

46. Colao A, Petersenn S, Newell-Price J, Findling JW, Gu F, Maldonado M, et al. Pasireotide B2305 Study Group. A 12-month phase 3 study of pasireotide in Cushing's disease. New Engl J Med. (2012) 366:914-24. doi: 10.1056/NEJMoa1105743

47. Webb SM, Ware JE, Forsythe A, Yang M, Badia X, Nelson LM, et al. Treatment effectiveness of pasireotide on health-related quality of life in patients with Cushing's disease. Eur J Endocrinol. (2014) 171:89-98. doi: 10.1530/EJE-13-1013

48. Fleseriu M, Biller BMK, Findling JW, Molitch ME, Schteingart DE, Gross C. Mifepristone, a glucocorticoid receptor antagonist, produces clinical and metabolic benefits in patients with Cushing's syndrome. J Clin Endocrinol Metab. (2012) 97:2039-49. doi: 10.1210/jc.2011-3350

49. van der Pas R, de Herder WW, Hofland LJ, Feelders RA. Cortisol diurnal rhythm and quality of life after successful medical treatment of Cushing's disease. Endocr Relat Cancer. (2012) 19:R205-23. doi: 10.1530/ERC-12-0191

50. Sonino N, Fava GA. Psychiatric disorders associated with Cushing's syndrome: epidemiology, pathophysiology and treatment. CNS Drugs. (2001) 15:361-73. doi: 10.2165/00023210-200115050-00003

51. Santos A, Resmini E, Crespo I, Pires P, Vives-Gilabert Y, Granell E, et al. Small cerebellar cortex volume in patients with active Cushing's syndrome. Eur J Endocrinol. (2014) 171:461-9. doi: 10.1530/EJE-14-0371

52. Mazet P, Simon D, Luton JP, Bricaire H: Psychic symptoms and personality of 50 patients with Cushing's syndrome (author's transl) (in French). Nouv Presse Med. (1981) 10:2565-70.

53. Dorn LD, Burgess ES, Dubbert B, Simpson SE, Friedman T, Kling M et al. Psychopathology in patients with endogenous Cushing's syndrome: atypical or melancholic features. Clin Endocrinol. (1995) 43:433-42. doi: 10.1111/j.1365-2265.1995.tb02614.x

54. Loosen PT, Chambliss B, DeBold CR, Shelton R, Orth DN. Psychiatric phenomenology in Cushing's disease. Pharmacopsychiatry. (1992) 25:192-8. doi: 10.1055/s-2007-1014405

55. Kelly WF. Psychiatric aspects of Cushing's syndrome. Q J Med. (1996) 89:543-51. doi: 10.1093/qjmed/89.7.543
56. Haskett RF. Diagnostic categorization of psychiatric disturbance in Cushing's syndrome. Am J Psychiatry. (1985) 142:911-6. doi: 10.1176/ajp.142.8.911

57. Hudson JI, Hudson MS, Griffing GT, Melby JC, Pope HG Jr. Phenomenology and family history of affective disorder in Cushing's disease. Am J Psychiatry. (1987) 144:951-3. doi: 10.1176/ajp.144.7.951

58. Forget H, Lacroix A, Somma $M$, Cohen H. Cognitive decline in patients with Cushing's syndrome. J Int Neuropsychol Soc. (2000) 6:20-9. doi: 10.1017/S1355617700611037

59. León-Carrión J, Atutxa AM, Mangas MA, Soto-Moreno A, Pumar A, LeonJustel A, et al. A clinical profile of memory impairment in humans due to endogenous glucocorticoid excess. Clin Endocrinol. (2009) 70: 192-200. doi: 10.1111/j.1365-2265.2008.03355.x

60. Mauri M, Sinforiani E, Bono G, Vignati F, Berselli ME, Attanasio R, et al. Memory impairment in Cushing's disease. Acta Neurol Scand. (1993) 87:525. doi: 10.1111/j.1600-0404.1993.tb04075.x

61. Starkman MN, Giordani B, Berent S, Schork MA, Schteingart DE. Elevated cortisol levels in Cushing's disease are associated with cognitive decrements. Psychosomatic Med. (2001) 6:3 985-93. doi: 10.1097/00006842-200111000-00018

62. Michaud K, Forget H, Cohen H. Chronic glucocorticoid hypersecretion in Cushing's syndrome exacerbates cognitive aging. Brain Cogn. (2009) 71:1-8. doi: 10.1016/j.bandc.2009.02.013

63. Resmini E, Santos A, Webb SM. Cortisol excess and the brain. Front Horm Res. (2016) 46:74-86. doi: 10.1159/000443868

64. Starkman MN, Gebarski SS, Berent S, Schteingart DE. Hippocampal formation volume, memory dysfunction, and cortisol levels in patients with Cushing's syndrome. Biol Psychiatry. (1992) 32:756-65. doi: 10.1016/0006-3223(92)90079-F

65. Santos A, Granell E, Gómez-Ansón B, Crespo I, Pires P, Vives-Gilabert $\mathrm{Y}$, et al. Depression and anxiety scores are associated with amygdala volume in Cushing's syndrome: preliminary study. Biomed Res Int. (2017) 2017:2061935. doi: 10.1155/2017/2061935

66. Merke DP, Giedd JN, Keil MF, Mehlinger SL, Wiggs EA, Holzer S, et al. Children experience cognitive decline despite reversal of brain atrophy one year after resolution of Cushing syndrome. J Clin Endocrinol Metab. (2005) 90:2531-6. doi: 10.1210/jc.2004-2488

67. Khiat A, Bard C, Lacroix A, Rousseau J, Boulanger Y. Brain metabolic alterations in Cushing's syndrome as monitored by proton magnetic resonance spectroscopy. NMR Biomed. (1999) 12:357-63. doi: 10.1002/(SICI)1099-1492(199910)12:6<357::AID-NBM584>3.3.CO;2-L

68. Pires P, Santos A, Vives-Gilabert Y, Webb SM, Sainz-Ruiz A, Resmini E, et al. White matter alterations in the brains of patients with active, remitted, and cured Cushing syndrome: a DTI study. AJNR Am J Neuroradiol. (2015) 36:1043-8. doi: 10.3174/ajnr.A4322

69. Langenecker SA, Weisenbach SL, Giordani B, Briceño EM, Guidotti Breting LM, Schallmo MP, et al. Impact of chronic hypercortisolemia on affective processing. Neuropharmacology. (2012) 62:217-25. doi: 10.1016/j.neuropharm.2011.07.006

70. Starkman MN, Schteingart DE, Schork MA. Depressed mood and other psychiatric manifestations of Cushing's syndrome: relationship to hormone levels. Psychosom Med. (1981) 43:3-18. doi: 10.1097/00006842-198102000-00002

71. Magiakou MA, Mastorakos G, Oldfield EH, Gomez MT, Doppman JL, Cutler GB Jr., et al. Cushing's syndrome in children and adolescents. Presentation, diagnosis, and therapy. N Engl J Med. (1994) 331:629-36. doi: 10.1056/NEJM199409083311002

72. Keil MF. Quality of life and other outcomes in children treated for cushing syndrome. J Clin Endocrinol Metab. (2013) 98:2667-78. doi: $10.1210 /$ jc.2013-1123

73. Maheu FS, Mazzone L, Merke DP, Keil MF, Stratakis CA, Pine DS, et al. Altered amygdala and hippocampus function in adolescents with hypercortisolemia: a functional magnetic resonance imaging study of Cushing syndrome. Dev Psychopathol. (2008) 20:1177-89. doi: 10.1017/S0954579408000564

74. Sippel RS, Elaraj DM, Kebebew E, Lindsay S, Tyrrell JB, Duh QY. Waiting for change: symptom resolution after adrenalectomy for Cushing's syndrome. Surgery. (2008) 144:1054-60. doi: 10.1016/j.surg.2008.08.024 
75. Nader S, Burkhardt T, Vettorazzi E, Milian M, Aberle J, Petersenn $S$, et al. Health-related quality of life in patients after treatment of Cushing's disease. Exp Clin Endocrinol Diabetes. (2016) 124:187-91. doi: 10.1055/s-0035-1569340

76. Heald AH, Ghosh S, Bray S, Gibson C, Anderson SG, Buckler H, et al. Long-term negative impact on quality of life in patients with successfully treated Cushing's disease. Clin Endocrinol. (2004) 61:458-65. doi: 10.1111/j.1365-2265.2004.02118.x

77. van der Klaauw AA, Kars M, Biermasz NR, Roelfsema F, Dekkers OM, Corsmitt EP, et al. Disease-specific impairments in quality of life during long-term follow-up of patients with different pituitary adenomas. Clin Endocrinol. (2008) 69:775-84. doi: 10.1111/j.1365-2265.2008.03288.x

78. Tiemensma J, Daskalakis NP, van der Veen EM, Ramondt S, Richardson SK, Broadbent E, et al. Drawings reflect a new dimension of the psychological impact of long-term remission of Cushing's syndrome. J Clin Endocrinol Metab. (2012) 97:3123-31. doi: 10.1210/jc.2012-1235

79. Papakokkinou E, Johansson B, Berglund P, Ragnarsson O. Mental fatigue and executive dysfunction in patients with Cushing's syndrome in remission. Behav Neurol. (2015) 2015:173653. doi: 10.1530/endoabs.37.GP.21.05

80. Hawn MT, Cook D, Deveney C, Sheppard BC. Quality of life after laparoscopic bilateral adrenalectomy for Cushing's disease. Surgery. (2002) 132:1064-8. doi: 10.1067/msy.2002.128482

81. Tiemensma J, Biermasz NR, Middelkoop HA, van der Mast RC, Romijn JA, Pereira AM. Increased prevalence of psychopathology and maladaptive personality traits after long-term cure of Cushing's disease. J Clin Endocrinol Metab. (2010) 95:E129-41. doi: 10.1210/jc.2010-0512

82. Ragnarsson O, Berlund P, Eder DN, Johannsson G. Long-term cognitive impairments and attentional deficits in patients with Cushing's disease and cortisol-producing adrenal adenoma in remission. J Clin Endocrinol Metab. (2012) 97:E1640-8. doi: 10.1210/jc.2012-1945

83. Tiemensma J, Kaptein AA, Pereira AM, Smit JW, Romijn JA, Biermasz NR. Coping strategies in patients after treatment for functioning or nonfunctioning pituitary adenomas. J Clin Endocrinol Metab. (2011) 96:96471. doi: 10.1210/jc.2010-2490

84. Andela CD, Niemeijer ND, Scharloo M, Tiemensma J, Kanagasabapathy S, Pereira AM et al. Towards a better quality of life (QoL) for patients with pituitary diseases: results from a focus group study exploring QoL. Pituitary. (2015) 18:86-100. doi: 10.1007/s11102-014-0561-1

85. Dorn LD, Cerrone P. Cognitive function in patients with Cushing syndrome: a longitudinal perspective. Clin Nurs Res. (2000) 9:420-40. doi: $10.1177 / 10547730022158672$

86. Forget H, Lacroix A, Cohen H. Persistent cognitive impairment following surgical treatment of Cushing's syndrome. Psychoneuroendocrinology. (2002) 27:367-83. doi: 10.1016/S0306-4530(01)00059-2

87. Tiemensma J, Koksoorn NE, Biermasz NR, Keijser BJ, Wassenaar MJ, Middelkoop HA, et al. Subtle cognitive impairments in patients with longterm cure of Cushing's disease. J Clin Endocrinol Metab. (2010) 95:2699-714. doi: $10.1210 /$ jc. $2009-2032$

88. Crespo I, Granell-Moreno E, Santos A, Valassi E, De Juan-Delago M, VivesGilabert Y, et al. Impaired decision-making process and thinner prefrontal cortex in patients with Cushing's syndrome. Clin Endocrinol. (2014) 81:82633. doi: $10.1111 /$ cen. 12564

89. Bas-Hoogendam JM, Andela CD, van der Werff SJ, Pannekoek JN, van Steenbergen H, Meijer OC, et al. Altered neural processing of emotional faces in remitted Cushing's disease. Psychoneuroendocrinology. (2015) 59:134-46. doi: 10.1016/j.psyneuen.2015.05.001

90. van der Werff SJ, Pannekoek JN, Andela CD, Meijer OC, van Buchem MA, Rombouts SA, et al. Resting-state functional connectivity in patients with long-term remission of Cushing's disease. Neuropsychopharmacology. (2015) 40:1888-98. doi: 10.1038/npp.2015.38

91. Pires P, Santos A, Vives-Gilabert Y, Webb SM, Sainz-Ruiz A, Resmini E, et al. White matter involvement on DTI-MRI in Cushing's syndrome relates to mood disturbances and processing speed: a case-control study. Pituitary. (2017) 20:340-8. doi: 10.1007/s11102-017-0793-y
92. Resmini E, Santos A, Gómez-Anson B, López-Mourelo O, Pires P, VivesGilabert Y, et al. Hippocampal dysfunction in cured Cushing's syndrome patients, detected by 1H-MR spectroscopy. Clin Endocrinol. (2013) 79:700-7. doi: $10.1111 /$ cen. 12224

93. Crespo I, Santos A, Gómez-Ansón B, López-Mourelo O, Pires P, Vives-Gilabert Y, et al. Brain metabolite abnormalities in ventromedial prefrontal cortex are related to duration of hypercortisolism and anxiety in patients with Cushing's syndrome. Endocrine. (2016) 53:848-56. doi: 10.1007/s12020-016-0963-0

94. Bourdeau I, Bard C, Noël B, Leclerc I, Cordeau MP, Bélair M, et al. Loss of brain volume in endogenous Cushing's syndrome and its reversibility after correction of hypercortisolism. J Clin Endocrinol Metab. (2002) 87:1949-54. doi: $10.1210 /$ jcem.87.5.8493

95. Starkman MN, Giordani B, Gebarski SS, Schteingart DE. Improvement in learning associated with increase in hippocampal formation volume. Biol Psychiatry. (2003) 53:233-8. doi: 10.1016/S0006-3223(02)01750-X

96. Starkman MN, Giordani B, Gebarski SS, Schteingart DE. Improvement in mood and ideation associated with increase in right caudate volume. J Affect Disord. (2007) 101:139-47. doi: 10.1016/j.jad.2006.11.007

97. Resmini E, Santos A, Gómez-Anson B, Vives Y, Pires P, Crespo I, et al. Verbal and visual memory performance and hippocampal volumes, measured by 3 Tesla magnetic resonance imaging, in patients with Cushing's syndrome. $J$ Clin Endocrinol Metab. (2012) 97:663-71. doi: 10.1210/jc.2011-2231

98. Keil MF, Merke DP, Gandhi R, Wiggs EA, Obunse K, Stratakis CA. Quality of life in children and adolescents 1-year after cure of Cushing syndrome: a prospective study. Clin Endocrinol. (2009) 71:326-33. doi: 10.1111/j.1365-2265.2008.03515.x

99. Leong GM, Abad V, Charmandari E, Reynolds JC, Hill S, Chrousos GP et al. Effects of child- and adolescent-onset endogenous Cushing syndrome on bone mass, body composition, and growth: a 7-year prospective study into young adulthood. J Bone Miner Res. (2007) 22:110-8. doi: 10.1359/jbmr.061010

100. Magiakou MA, Mastorakos G, Chrousos GP. Final stature in patients with endogenous Cushing's syndrome. J Clin Endocrinol Metab. (1994) 79:1082-5. doi: $10.1210 /$ jcem.79.4.7962277

101. Chipidza FE, Wallwork RS, Stern TA. Impact of the doctorpatient relationship. Prim Care Companion CNS Disord. (2015) 17:10.4088/PCC.15f01840. doi: 10.4088/PCC.15m01840

102. Martinez-Momblan MA, Gomez C, Santos A, Porta N, Esteve J, Ubeda I, et al. A specific nursing educational program in patients with Cushing's syndrome. Endocrine. (2015) 53:199-209. doi: 10.1007/s12020-015-0737-0

103. Nieman LK, Biller BM, Findling JW, Murad MH, Newell-Price J, Savage MO et al. Treatment of Cushing's syndrome: an Endocrine Society clinical practice guideline. J Clin Endocrinol Metab. (2015) 100:2807-31. doi: $10.1210 /$ jc.2015-1818

104. Etxabe J, Vazquez JA. Morbidity and mortality in Cushing disease: an epidemiological approach. Clin Endocrinol. (1994) 40:479-84. doi: 10.1111/j.1365-2265.1994.tb02486.x

105. Kreitschmann-Andermahr I, Siegel S, Gammel C, Campbell K, Edwin L, Grzywotz A, et al. Support needs of patients with Cushing's disease and Cushing's syndrome: results of a survey conducted in Germany and the USA. Int J Endocrinol. (2018) 2018:9014768. doi: 10.1155/2018/9014768

Conflict of Interest: The authors declare that the research was conducted in the absence of any commercial or financial relationships that could be construed as a potential conflict of interest.

Copyright (C) 2019 Santos, Resmini, Martínez Momblán, Valassi, Martel and Webb. This is an open-access article distributed under the terms of the Creative Commons Attribution License (CC BY). The use, distribution or reproduction in other forums is permitted, provided the original author(s) and the copyright owner(s) are credited and that the original publication in this journal is cited, in accordance with accepted academic practice. No use, distribution or reproduction is permitted which does not comply with these terms. 